\title{
Measuring the Internet Skills of Gen Z Students in Higher Education: Validation of the Internet Skills Scale in University Settings
}

\author{
Ourania Miliou, Charoula Angeli \\ Department of Education, University of Cyprus, Cyprus.
}

\begin{abstract}
Internet technologies have infiltrated higher education institutions around the world. At the same time, the latest generation of students, the so-called Generation Z (Gen Z), are entering higher education. Gen $Z$ is the first generation born in an Internet-connected world, and digital devices are a seamless part of its life. As a result, Gen $Z$ students have already been engaged with informal digital learning via internet-based technologies outside of formalized education settings. However, previous research has shown that their engagement with these technologies is limited and might not sufficiently cover the knowledge and skills needed to perform internet activities effectively in higher education. Additionally, their familiarity with digital devices and tools varies. Consequently, there is a need for higher education institutions to close the skills gap by applying assessment processes that will assist them in forming policies and training resources for undergraduate students. To achieve the above, research efforts need to focus on developing theoretically informed and valid instruments that measure internet skills. This study has contributed to the validation of a self-assessment questionnaire, the Internet Skills Scale, that can be used in university settings. The questionnaire measures five types of internet skills: operational, information-navigation, social, creative, and critical. The results presented herein provide directions for future research in the field.
\end{abstract}

Keywords: Internet skills; Internet skills scale; validation; generation Z; higher education. 


\section{Introduction}

Today's university students belong to the so-called Generation Z. This generation was born in the 1990s and has experienced a globally connected world where the Internet has always been available (Seemiller, \& Grace, 2016). As a result, this generation, who is also reffered to as "digital natives", has already used various digital technologies from a very young age, and the Internet is a seamless part of its life (Seemiller \& Grace, 2016; Mohr \& Mohr, 2017). Although young people's use of digital technologies takes place outside formal education settings, such technologies are also an essential part of their academic lives (Bullen, Morgan, \& Qayyum, 2011; Ng, 2012; Ting, 2015; Brooks, 2016; Alexander, Becker, Cummins, \& Giesinger, 2017). Despite that, research indicates that informal experiences with digital technologies do not necessarily suggest that undergraduate students can use such technologies for academic purposes (Kennedy \& Fox, 2013; Šorgo, Bartol, Dolničar, \& Boh Podgornik, 2017). One explanation for this may be that such learning experiences might not sufficiently cover all the skills an individual must acquire to exploit the full potential of digital technologies (van Laar, van Deursen, van Dijk \& de Haan 2017). Concequently, many students enter higher education institutions with limited digital skills (Sewlyn, 2009; Ng, 2012; Ståhl, 2017). Additionally, the level of students' digital skills and their familiarity with digital devices and tools varies (Helsper \& Eynon, 2010; Hagittai, 2010; Corrin, Bennett, \& Lockyer, 2010).

It is widely recognized by higher education institutions and organizations that digital skills are considered an essential component of the human capital, and highly competent users are thus in a better position to be benefited (van Laar, van Deursen, van Dijk, \& de Haan 2017). According to forecasts of the European Commission, the future workforce is expected to possess a basic level of digital skills for at least $90 \%$ of the professions in the future (European Commission, 2017). In this regard, there is a need for universities to ensure that graduates possess the skills that will enable them to leverage digital technologies and prepare them for the labour market (Jørgensen, 2019).

Hence, research efforts need to provide valid and reliable measures that assess students' needs in advance (Litt, 2013; Ting, 2015). The identification of student's needs will allow higher education institutions to enhance their responsiveness and adaptability and promote programmes for the effective and productive use of digital technologies in the academic environment (Brooks, 2016).

\section{Theoretical Background}

At an academic level, the effective use of the Internet is essential because it is the primary medium that students regularly use to access course materials and other information resources, communicate with their peers and professors and conduct course work (Kennedy 
\& Fox, 2013; Gosper, Malfroy \& McKenzie, 2013; Shopova, 2014). Research has shown that young people easily adapt to the use of the Internet at a technical level (e.g. accessing services, connecting to a WiFi network) (Kennedy \& Fox, 2013; Ng, 2012). In addition, they are very familiar with the use of internet technologies for communication purposes (Bullen, Morgan, \& Qayyum, 2011; Gosper, Malfroy \& McKenzie, 2013; Shopova, 2014). However, they seem to experience difficulties using tools and services for online information search and evaluation (Hargittai, Fullerton, Menchen-Trevino, \& Thomas 2010; Head, 2013; Neumann, 2016) and content creation (Ng, 2012; Kennedy \& Fox, 2013). In this regard, there is a need for higher education institutions to close the internet skills gap (Helsper \& Eynon, 2010; Hargittai, 2010) by applying assessment processes that will assist them in forming policies and training resources for undergraduate students (Litt, 2013).

One of the most comprehensive and updated measures for assessing the above skills areas is the Internet Skills Scale (ISS) which is proposed by Van Deursen, Helsper and Eynon (2014.2016). The development of ISS is based on a theoretical framework which includes four types of skills: Operational, Information Navigation, Social and Creative. Operational skills refer to the most basic technical skills required to use the Internet, such as using browsers to access web applications. The Information Navigation skills refer to navigating through various websites with different layouts and searching, selecting and evaluating the information on the Internet. Social skills relate to using online communication services, interacting with others and exchanging meaning. Lastly, Creative skills are the skills someone needs to create different types of acceptable quality content (e.g. text, audio, video) and publish it or share it with others on the Internet (Van Deursen, Helsper, \& Eynon, 2014. 2016).

The ISS was developed to measure the general population's internet skills, including young people. The study herein aims to theoretically inform the ISS and provide a reliable and updated measure that can assess nationally representative samples and other subpopulations, namely undergraduate students. In this regard, it will allow for better comparisons between demographics that help future researchers to determine how different aspects of internet skills vary among groups (Litt, 2013).

\section{Research Methodology}

The study sample included 180 undergraduate students who were attending courses at the University of Cyprus during the academic year 2017-2018. Approximately $30 \%$ of the students were males, and 70\% were females. Additionally, 58.3\% belonged to the $18-20$ age group, $33.4 \%$ to the $21-23$ age group, while a small percentage of $8.3 \%$ belonged to the 24 25 age group. Finally, $23.9 \%$ were first-year students, $31.1 \%$ were in the second year, $26.7 \%$ 
were in the third year, $14.4 \%$ were in the fourth year, and the remaining $3.9 \%$ were in the firth year of study and above.

\subsection{Description of the Internet Skills Scale}

The original Scale includes 35 proposed Likert-scale items on five skills categories: Operational, Information Navigation, Social, Creative and Mobile. The category "mobile skills" (three items) was excluded because the importance of and distribution of skills in using mobile devices was not in this study's scope. Additionally, Van Deursen, Helsper and Eynon (2014) proposed future studies to include new items, such as "critical skills" which refer to the process of evaluation. For this reason, two "critical skills" items were included which were suited for the study's context (I am confident in selecting search results, I carefully consider the information I find online). 
Table 1. Proposed Items for the Internet Skills Scale

\begin{tabular}{|c|c|}
\hline Skills & Items \\
\hline Operational & $\begin{array}{l}\text { 1. I know how to open a new tab in my browser. } \\
\text { 2. I know where to click to go to a different webpage. } \\
\text { 3. I know how to bookmark a website. } \\
\text { 4. I know how to use shortcut keys (e.g. CTRL-C for copy, CTRL-S for save) } \\
\text { 5. I know how to download/save a photo I found online. } \\
\text { 6. I know how to open downloaded files. } \\
\text { 7. I know how to complete online forms. } \\
\text { 8. I know how to upload files. } \\
\text { 9. I know how to connect to a WIFI network. } \\
\text { 10. I know how to adjust privacy settings. }\end{array}$ \\
\hline $\begin{array}{l}\text { Information } \\
\text { Navigation }\end{array}$ & $\begin{array}{l}\text { 11. Sometimes I end up on websites without knowing how I got there. } \\
\text { 12. I find it hard to find a website I visited before. } \\
\text { 13. I find the way in which many websites are designed confusing. } \\
\text { 14. All the different website layouts make working with the internet difficult for me. } \\
\text { 15. I get tired when looking for information online. } \\
\text { 16. I should take a course on finding information online. } \\
\text { 17. I find it hard to decide what the best keywords are to use for online searches. } \\
\text { 18. Sometimes I find it hard to verify information I have retrieved. }\end{array}$ \\
\hline Social & $\begin{array}{l}\text { 19. I know which information I should and shouldn't share online. } \\
\text { 20.I know when I should and shouldn't share information online. } \\
\text { 21. I am careful to make my comments and behaviours appropriate to the situation } \\
\text { I find myself in online. } \\
\text { 22. I know how to change who I share content with (e.g. friends, friends of friends } \\
\text { or public). } \\
\text { 23.I know how to remove friends from my contact lists. } \\
\text { 24. I feel comfortable deciding who to follow online (e.g. on services like Twitter } \\
\text { or Tumblr). }\end{array}$ \\
\hline Creative & $\begin{array}{l}\text { 25. I would feel confident writing and commenting online. } \\
\text { 26. I am confident about writing a comment on a blog, website or forum. } \\
\text { 27. I know how to create something new from existing online images, music or } \\
\text { video. } \\
\text { 28. I know how to make basic changes to the content that others have produced. } \\
\text { 29.I would feel confident putting video content I have created online. } \\
\text { 30. I know how to design a website. } \\
\text { 31. I know which different types of licences apply to online content. } \\
\text { 32. I know which apps/software are safe to download. }\end{array}$ \\
\hline Critical & $\begin{array}{l}\text { 33. I am confident in selecting search results. } \\
\text { 34. I carefully consider the information I find online. }\end{array}$ \\
\hline
\end{tabular}




\subsection{Preparation for the validation process}

For validation purposes, the original items of the Scale were translated into Greek from two experts in Technology, who then discussed and resolved the discrepancies. A back-ward translation was followed, and the final version of the translated questionnaire was pilot tested on a small sample.

Prior to analysis, descriptive statistics were performed for each questionnaire items to determine whether there were any floor or ceiling effects in the questionnaire. While most of the items performed well, some of the items had very strong ceiling effects. In particular, ceiling effects were evident in six questions of the operational skills set (I know how to open a new tab in my browser (1), I know where to click to go to a different webpage (2), I know how to open downloaded files (6), I know how to download/save a photo I fould online (5), I know how to connect to a WIFI network (9), I know how to upload files (8)). Additionally, the same effects were evident in one question of the social skills set (I know how to remove friends from my contact lists (23)). This finding is consistent with literature that suggests that younger generations, due to their familiarity and frequent use of the Internet, have already acquired basic technical knowledge (Ng, 2012; Kennedy \& Fox, 2013; Ting, 2015; Ståhl, 2017). Because of these ceiling effects, it was considered more appropriate for these items to be removed from the scale.

\section{Results}

In order to validate the construct validity of the constructs measured in the Internet Skills Scale, we performed an Exploratory Factor Analysis (EFA) in the remaining 27 items of the Scale with SPSS 24.

Initially, we examined the suitability of the data for factor analysis. The correlation matrix indicated that there were many correlations with a coefficient greater than 0.30 (and no correlation with a coefficient greater than 0.90 ). The KMO had an initial value of 0.87 and the Bartlett's test suggested rejecting the null hypothesis at the level of $\alpha=.01$. Factor analysis resulted in a 27 -item scale with five subscales: Information-Navigation, Social, Creative, Operational and Critical. Results from the reliability analysis showed that all five factors had high internal reliability (Cronbach's alpha is 0.90 for the first factor, 0.89 for the second factor, 0.91 for the third factor, 0.84 for the fourth factor and 0.87 for the fifth factor). 
Table 2. Mean, Standard Deviation and Reliability Values for each Construct $(\mathrm{N}=\mathbf{1 8 0})$.

\begin{tabular}{lcccc}
\hline \multicolumn{1}{c}{ Factors } & Items**** & $\overline{\mathbf{x}}$ & SD & alpha \\
\hline Information Navigation & $11,12,13,14,15,16,17$ & 15.39 & 6.11 & 0.90 \\
Social & $19,20,21,22,24,25,26$ & 27.41 & 5.50 & 0.89 \\
Creative & $27,28,29,30,31$ & 11.80 & 5.66 & 0.91 \\
Operational & $3,4,10,7$ & 16.21 & 3.31 & 0.84 \\
Critical & $18,32,33,34$ & 14.53 & 3.64 & 0.87 \\
\hline
\end{tabular}

*The number of each item, as it appears in Table 1.

**The Information Navigation items were reversed since they were negatively worded.

The use of principal component analysis for factor extraction suggested the presence of five factors with eigenvalues $>1$, which together accounted for $70.3 \%$ of the variance $(38.9 \%$, $13.8 \%, 7.4 \%, 6.2 \%$ and $4 \%$, respectively). For the best interpretation of the factors, the initial pattern matrix was rotated orthogonally using varimax rotation.

The first factor, Information-Navigation skills, explained $38.9 \%$ of the variance and was composed of seven items with factor loadings .536 to .904 . It is important to note that most of the highest loading items refer to navigation. The second factor, Social skills, explained $13.8 \%$ of the variance and loaded clearly with seven items with factor loadings .648 to .810 . Although in the original Scale, the items 25 and 26 loaded higher on the Creative skills factor, in this study they loaded higher on the Social skills factor. The third factor, Creative skills, explained $7.4 \%$ of the variance and was composed of five items with factor loadings .766 to .879 . The fourth factor, Operational skills, explained $6.2 \%$ of the variance and was composed of four items with factor loadings .527 to .849 . Lastly, the fifth factor, Critical skills, explained $4 \%$ of the variance and was composed of four items with factor loadings .565 to .664 . The Critical skills set has formed a fifth factor, although the framework refers to the processes of evaluation as part of the Information Navigation skills. However, it is worth noting that two of the items, 18 and 33 in the Critical skills factor load (more than 0.5) to the Information Navigation skills factor.

\section{Discussion}

Internet skills research could benefit from developing measures that show reliability and validity. This study performed an Exploratory Factor Analysis to adapt and validate the Internet Skills Scale to the context of higher education in Cyprus. The results produced four factors that remained relatively consistent with the original Scale. The addition of the "critical skills" items resulted in the composition of a new factor and a new set of skills, as the authors of the original Scale suggested. The results from the descriptive analysis showed that the highest ratings were given to items from the Operational and Social skills sets, all of them 
referring to technical skills. Some items from the Information-Navigation skills set referring to navigation were rated high, while one item referring to information search was among the ones that were given very low ratings. Similarly, low ratings were given to items from the Creative and Critical skills sets. However, similar percentages in a range of responses showed that individual differences exist in different skills sets. The fact above confirms the heterogeneity of skills possessed by younger generations, and it is essential to be considered by higher education institutions. Future work needs to analyse the Scale's robustness with different academic groups, to improve the available instrument. Also, further research should examine the relationship between Critical and Information-Navigation skills. Moreover, other Operational skills could be explored, such as safe browsing, or Information-Navigation skills, such as avoiding plagiarism when using online information resources, which are essential for academic environments.

\section{References}

Alexander, B., Adams Becker, S., Cummins, M. \& Hall Giesinger, C. (2017). Digital Literacy in Higher Education, Part II: An NMC Horizon Project Strategic Brief. Austin, Texas: The New Media Consortium. (Volume 3.4, August 2017). Retrieved from: https:/www.learntechlib.org/p/182086/.

Brooks, C. (2016). ECAR Study of Undergraduate Students and Information Technology, 2016. Research report. Retrieved from: https://library.educause.edu/ /media/files/library/2014/10/ers1406-pdf.pdf?la=en.

Bullen, M., Morgan, T. \& Qayyum, A. (2011). Digital learners in Higher Education: Generation is Not the Issue. Canadian Journal of Learning Technology, 37(1). Retrieved from: https://www.learntechlib.org/p/42755/.

Corrin, L., Bennett, S., \& Lockyer, L. (2010). Digital Natives: Everyday life versus academic study. Proceedings of the 7th International Conference on Networked Learning. 643-650. Retrieved

from: https://ro.uow.edu.au/cgi/viewcontent.cgi?article=1214\&context=edupapers.

European Commission (2017). ICT for Work: Digital Skills in the Workplace. doi: $10.2759 / 498467$.

Gosper, M., Malfroy, J., \& McKenzie, J. (2013). Students' experiences and expectations of technologies: An Australian study designed to inform planning and development decisions. Australasian Journal of Educational Technology,29(2), 268-282. doi: 10.14742/ajet.127.

Hargittai, E., Fullerton, L., Menchen-Trevino, E., \& Thomas, K. Y. (2010). Trust online: Young adults' evaluation of web content. International journal of communication, 4(1), 468-494.

Hargittai, E. (2010). Digital na (t) ives? Variation in Internet Skills and Uses Among Members of the "Net Generation". Sociological inquiry, 80(1), 92-113. doi: 10.1111/j.1475-682X.2009.00317.x. 
Head, A. (2013). Learning the ropes: How freshmen conduct course research once they enter college. Retrieved from: https://files.eric.ed.gov/fulltext/ED548262.pdf

Helsper, E. J., \& Eynon, R. (2010). Digital natives: where is the evidence? British educational research journal, 36(3), 503-520. doi: 10.1080/01411920902989227.

Jørgensen, T. (2019). Digital Skills: Where Universities Matter. Retrieved from: https://eua.eu/downloads/publications/digital\%20skills\%20\%20where $\% 20$ universities $\%$ 20matter.pdf.

Kennedy, D. M., \& Fox, R. (2013). 'Digital natives': An Asian perspective for using learning technologies. International Journal of Education and Development using ICT, 9(1), 6579.

Litt, E. (2013). Measuring users' internet skills: A review of past assessments and a look toward the future. New Media \& Society, 15(4), 612-630. doi: $10.1177 / 1461444813475424$.

Mohr, K. A., \& Mohr, E. S. (2017). Understanding Generation Z students to promote a contemporary learning environment. Journal on Empowering Teaching Excellence, 1(1), 9. doi: 10.15142/T3M05T.

Neumann, C. (2016). Teaching digital natives: Promoting information literacy and addressing instructional challenges. Reading Improvement, 53(3). 101-106.

$\mathrm{Ng}$, W. (2012). Can we teach digital natives digital literacy?. Computers \& Education, 59(3), 1065-1078. doi: 10.1016/j.compedu.2012.04.016.

Seemiller, C., \& Grace, M. (2016). Generation Z goes to college. San Francisco: John Wiley $\&$ Sons.

Selwyn, N. (2009). The digital native - myth and reality. Aslib Proceedings, 61(4). 364379. doi: 10.1108/00012530910973776.

Shopova, T. (2014). Digital Literacy of Students and its Improvement at the University. Journal on Efficiency and Responsibility in Education and Science, 7(2), 2632. doi: 10.7160/eriesj.2014.070201.

Šorgo, A., Bartol, T., Dolničar, D., \& Boh Podgornik, B. (2017). Attributes of digital natives as predictors of information literacy in higher education. British Journal of Educational Technology, 48(3), 749-767. doi: 10.1111/bjet.12451.

Ståhl, T. (2017). How ICT savvy are Digital Natives actually?. Nordic Journal of Digital Literacy, 12(03), 89-108. doi: 10.18261/ISSN.1891-943X-2017-03-04.

Ting, Y. L. (2015). Tapping into students' digital literacy and designing negotiated learning to promote learner autonomy. The Internet and Higher Education, 26, 25-32. doi: 10.1016/j.iheduc.2015.04.004.

Van Deursen, A. J., Helsper, E. J., \& Eynon, R. (2016). Development and validation of the Internet Skills Scale (ISS). Information, Communication \& Society, 19(6), 804-823. doi: 10.1080/1369118X.2015.1078834.

Van Deursen, A. J. A. M., Helsper, E. J., \& Eynon, R. (2014). Measuring digital skills. From digital skills to tangible outcomes. Project Report. Retrieved from: http://www.oii.ox.ac.uk/research/projects/?id=112. 
Van Laar, E., Van Deursen, A. J., Van Dijk, J. A., \& De Haan, J. (2017). The relation between 21st-century skills and digital skills: A systematic literature review. Computers in human behavior, 72, 577-588. doi: 10.1016/j.chb.2017.03.010. 